\title{
Hydatid Cyst of Radial Bone
}

\author{
Mondal SK, ${ }^{1}$ Sengupta SG ${ }^{1}$ \\ 'Department of Pathology Medical College Kolkata, Nepal.
}

\section{ABSTRACT}

Hydatidosis is a parasitic disease caused by Echinococcus granulosus or, less frequently Echinococcus multilocularis. The liver and lungs are most often affected; hydatid disease of radius without involvement of other sites is extremely rare. Osseous hydatid disease should be included in the differential diagnosis for cystic lesions of bone. The diagnosis of bone hydatidosis is primarily based on radiological and histopathological findings. Here we present a case of hydatid cyst in the lower third of radius in a 34 -year old woman. The cysts were removed with wide excision and post-operative albendazole was given. No recurrence was observed on two years follow-up.

Key Words: bone, hydatid cyst, radius

\section{INTRODUCTION}

Hydatid disease is caused by the tapeworm Echinococcus granulosus (larval stage) and man and domestic animals are affected by the parasite. It may occur due to ingestion of parasite's eggs directly from contact with infected dogs or from ingestion of contaminated water or food indirectly. As most larvae are trapped by the lung and liver when the embryos are released into the portal blood stream, the incidence of bone hydatidosis is very low.

Hydatid disease in bone, is very rare (1-2\% of all cases) and have been observed only in adults, with the spine, pelvis and long bones being the predominant locations. ${ }^{1,2}$ We describe an exceptional case of Hydatid disease involving the radius bone. To our knowledge, no such case has been previously reported in the literature.

\section{CASE REPORT}

A 34 year old lady attended orthopaedic out patient department with pain over her right forearm at its lower end for two months duration. Her medical history and general survey were unremarkable and physical examination revealed a mildly irregular tender bony swelling at the complained site. Radiology of the affected forearm showed multiple osteolytic cystic lesions in the

\section{Correspondence: \\ Dr. Santosh Kumar Mondal \\ Department of Pathology \\ Medical College Kolkata-73, India. \\ Email: dr_santoshkumar@hotmail.com \\ Phone:033-25472231}


metaphysis of radius (lower third) without any surrounding reactive sclerosis (Figure 1 ). No significant abnormalities were found on routine haematological investigations except for an increased erythrocyte sedimentation rate (ESR). A provisional clinical and radiological diagnosis of simple or aneurysmal bone cyst was made. Surgical exploration of the right radius revealed multiple metaphyseal cysts with fibrosis and abnormal scarring in the surrounding soft tissues. Wider extirpation of the macroscopically evident lesion including all the cysts and filling of the defect with bone grafts followed.

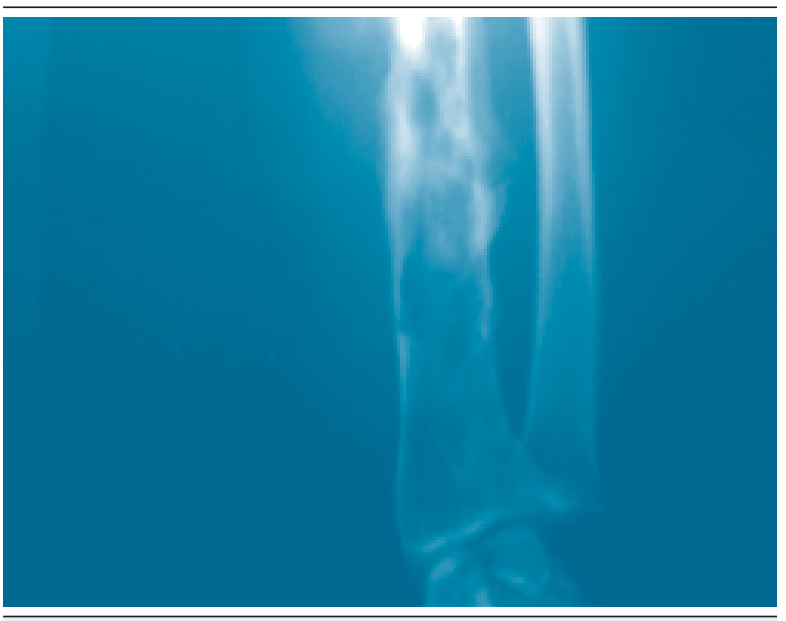

Figure 1. Radiograph showing multiple osteolytic cystic lesions in the lower part of radial bone.

The specimen comprising grossly whitish soft membrane/cartilage like material $(8 \mathrm{ml})$ revealed microscopically osseous tissue with characteristic lamellated hydatid cyst wall and prominent homogenous eosinophilic chitinous layer (Figure 2, 3). On subsequent ultrasonography (USG) and Computed Tomography (CT) scan, there was nothing suggestive of Hydatidosis in liver, lung or other organs. Presuming the prior surgery adequate, the patient was then treated with albendazole therapy $(10 \mathrm{mg} / \mathrm{kg} / \mathrm{day})$ for 12 weeks. She was followedup for next 24 months and there was no evidence of any recurrence or complication during that period.

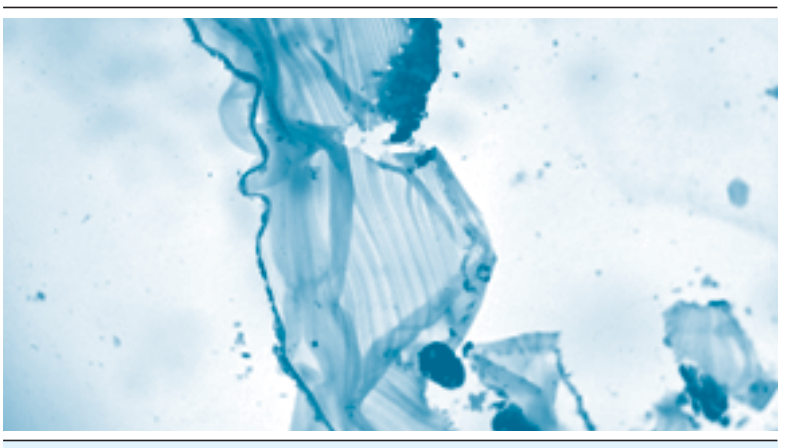

Figure 1. Photomicrograph showing lamellated hydatid cyst wall with prominent homogeneous chitinous layer. Multinucleated giant cells of osteoclastic type are also noted (H\&E, X100)

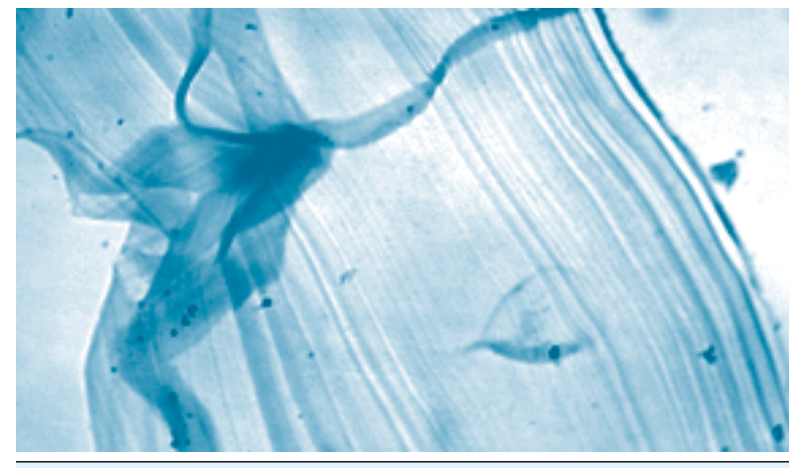

Figure 1. High power view of the same lesion (H\&E, X400)

\section{DISCUSSION}

The incidence of bone disease is extremely low as most larvae are trapped by the liver and lung upon release of embryo into the portal blood stream. As a result, the skeletal involvement is usually secondary to hepatic or pulmonary Hydatidosis, but it may present as primary disease as well. Cases have been reported in the vertebrae, the femur, the tibia and the pelvis but have not been reported in radius bone. It is often asymptomatic for a long duration and is usually detected after a sudden fracture, secondary infection or neurovascular lesion caused by compression. ${ }^{3,4}$ The diagnosis, obviously is difficult due to lack of typical features like daughter cysts, calcification, and germinal membrane detachment and the finally, the surprising yet common latency. ${ }^{5}$

The disease can mimic tuberculosis, simple bone cyst, sub-acute arthritis, giant cell tumors, malignant fibrous histiocytoma, myeloma and chondrosarcoma and should be suspected in any cystic lesions affecting the bone, especially in endemic areas. ${ }^{6-8}$ Diagnosis is mainly based on radiological findings and sometimes is established after surgery and histopathological examination (as in our case) which is definitive. ${ }^{5}$

Treatment is equally difficult because of the delay in diagnosis, the invasive nature of the bony involvement and the variable anaphylactic reaction to the cyst fluid antigen. Because of the poor results with medical treatment alone in reported cases, surgery remains the primary treatment and the only hope for complete cure..$^{5,9}$ And a more radical or wider resection is the preferred mode of surgery. ${ }^{5,9}$

Better forms of chemotherapy and newer methods, such as the puncture, aspiration, injection, and reaspiration (PAIR) technique are now available but need universal popularity. ${ }^{10}$ In the present case, we considered the extent of surgery, although done without the prior knowledge of proper diagnosis, were adequate and advised adjuvant chemotherapy with a 12 weeks course of albendazole.

\section{JNMA | Val 48}




\section{REFERENCES}

1. Fanian H, Marnani MK. A case report of hydatid disease in long bone. Journal of Research in Medical Sciences. 2005;10(2):101-4.

2. Ennouri S, Ayadi K, Ali HB, Mnif J. Hydatid cyst of the temporal bone: an exceptional location. AJR Am J Roentgenol. 2000 Sep;175(3):923-5.

3. Karray S, Zlitni M, Fowles JV, Zouari O, Slimane N, Kassab MT, et al. Vertebral hydatidosis and paraplegia. J Bone Joint Surg Br. 1990 Jan;72(1):84-8.

4. Knudsen C, Marks R, Learmonth GM. Orthopaedic hydatid disease. J Bone Joint Surg. 1988;70:504.

5. Zlitni M, Ezzaouia K, Lebib H, Karray M, Kooli M, Mestiri M. Hydatid cyst of bone: diagnosis and treatment. World J Surg. 2001 Jan;25(1):75-82.
6. Arti H, Daranti HY. Fibular hydatid cyst. Indian J Orthop. 2007;41:244-5.

7. Kalinova K, Proichev V, Stefanova P, Tokmakova K, Poriazova E. Hydatid bone disease: a case report and review of the literature. J Orthop Surg (Hong Kong). 2005 Dec;13(3):323-5.

8. Booz MK. Hydatid disease of bone in Kuwait with special reference to differential diagnosis. J Kuwait Med Assoc. 1968;2:27.

9. Herrera A, Martínez AA. Extra spinal bone hydatidosis. J Bone Joint Surg Am. 2003 Sep;85:1790-4.

10. Ammann RW, Eckert J. Cestodes: Echinococcus. Gastroenterol Clin North Am. 1996;25:655-89. 